other countries. The animal technician is coming to take his place alongside the laboratory technician as an indispensable member of the biological team.

The Committee has already given prominence to the need for national laboratory animal organizations, the four functions of which are : (a) to act as an exchange for information about all aspects of animal supply and management; (b) to conduct research into current problems in their production and care ; (c) to maintain primary type colonies of animals conforming to exacting specifications, supplying authentic breeding stock for expansion in production units; (d) to train scientists and technicians specializing in this field. For the future, it is planning a second symposium for some time in 1961, on transmissible disease (other than of genetic or nutritional origin); the preparation of world lists of primary type colonies of specified strains of animals, and sources of less commonly used species of vertebrates and invertebrates; as well as continuing the labours already undertaken.

The International Committee on Laboratory Animals started as an informal group, largely selfappointed, to examine a problem that was recognized in many quarters, namely the difficulty in obtaining enough laboratory animals of the right quality for current and future research. It is international in the sense that its membership and interests are already widespread, but it is not yet internationally representative. It is still self-recruiting, and no reason so far exists for it to be otherwise, for its present membership has a strong desire to attract the support of all who share its interests.

The very substantial support so far given by Unesco cannot be expected to continue indefinitely, and the grants given by the international unions are not, and probably never can be, sufficient to cover all its actual and intended activities. If the Committee is to carry on as it has started and to develop usefully, other international governmental agencies should be encouraged to help. Of these, the World Health Organization is an obvious candidate for patronage, because of its involvement in medical research, which is so vitally dependent on good laboratory animals. It is satisfactory to note that the World Health Organization has sent an observer to the last two meetings of the Committee.

It would also be reasonable to expect all countries supporting an active laboratory animals organization to have some representation on the Committee. At present only a few enjoy membership of the Committee, and these would appear to have been somewhat arbitrarily selected. There is little doubt that the lop-sidedness of the Committee, in this respect, will be corrected, and the sooner the better.

There is not only a need, but also great scope for international collaboration in defining and producing good laboratory animals. Without such collaboration there is a danger, already unhappily apparent in many parts of the world, of duplicated effort in solving the major problems in this field; of parallel but isolated developments in the use of animals which appear different but are similar, or appear similar but are differently or misleadingly designated; and of research effort being vitiated by the use of inadequate animal material. This fragmentation of endeavour has to be corrected before it goes too far. By the end of the decade we have just entered, we shall probably consider, in retrospect, our current ideas of quality in laboratory animals with astonishment bordering on incredulity that they served our purposes even as well as they do. If this is so, the International Committee on Laboratory Animals will have played an important part in our animal house revolution.

\title{
TRAINING SKILLED WORKERS
}

A LTHOUGH much is made of the skill of British craftsmen and operators, investigations over the past decade have shown how little is known about the components of skill. The result has been that much of the training provided for manual workers is conducted in a hit-or-miss fashion because those concerned with the training are not at all clear about the nature of the skill they are trying to impart and, consequently, even less clear about the teaching of it. One whose researches have been almost entirely concerned with the teaching of skills to unskilled and semi-skilled operatives in a variety of industries is W. D. Seymour, and, in a broadsheet published by the Institute of Personnel Management, he presents some of the experience he has gained in training unskilled and semi-skilled operatives in manufacturing industry. This broadsheet should be warmly welcomed by all concerned with the training of operatives as the clearest and most concise statement which has yet appeared.

The types of work customarily undertaken by unskilled and semi-skilled workers in manufacturing industry can be grouped into the following categories :

Handwork, that is, work which is done exclusively with the operators' bare hands, without the intervention of any tools or machinery. This group of operations still employs a large number of operators and includes wrapping and packing operations, some assembly work, pottery decoration and other examples of very fine work. Some types of inspection work also fall into this category.

Handwork with Tools. This eategory includes all types of manual work in which hand tools are used, but which do not involve the use of mechanical power. In spite of the increasing mechanization of modern industry, very large numbers of workers are still engaged in these operations with hand tools, which may be of a general nature, for example, screwdrivers and pliers, or may be specially designed for the purpose, for example, the wig-maker's hook. Examples of this type of work are provided by most types of assembly work, pottery figure making, automatic telephone wiring, coil fitting on electric motors, etc.

Single Purpose Machine Work. This category covers all operations where a mechanically or electrically driven machine is used for a single specific purpose. The increasing use of specialpurpose machines tends to augment the number of workers employed in this category, though the numbers employed on any one type of machine may be small. Examples are provided by hosiery seaming and linking machines, coil winding machines and cigar making machines. 
Multi-Purpose Machine Work. The category includes all types of work done on adaptable powerdriven machines, which can be used for a variety of purposes. Typical examples in this category are the capstan lathe and the industrial sewing machine.

Group Machine Work. This category includes those types of work where the operator is responsible for the output from a number or battery of machines, which are automatic or semi-automatic in their operation. Such work is sometimes referred to as machine minding, but frequently involves short complex operations which need to be done efficiently if full production is to be achieved. Automatic capstan. lathe work, weaving and spinning provide examples in this category.

Non-Repetitive Work. Operations in this category are frequently even more important than repetitive work and involve a high degree of responsibility; they include machine setting, loom overlooking or tackling and inspection operations and process work.

Techniques of operator training are now being used in a number of industries in Great Britain, and are also being adopted overseas. Underlying these techniques is the recognition that operator skills in industry are very varied and highly developed, and that training of new workers to aequire such skills must be based on an adequate analysis and understanding of the skills. Furthermore, training must be considered as continuing right up to the point where the new recruit attains the experienced workers' standard of output and quality. Where the skills analysis indicates that a task presents special difficulties of movement or of perception, exercises or devices are designed for preliminary training. Again, after further scrutiny of the analysis, the task is divided into sections suitable for training, special attention being given to those parts which involve perceptual difficulties or decision making. 'Target standards, equivalent to experienced workers' standards of output and quality, are determined for each section of the work. Trainees, normally in pairs and in a training centre adjacent to, but separate from, the shop, practise the preliminary exercises, then practise the sections of the job and proceed to perform the parts together only when each has been mastered to experienced workers' standard of output and quality. When one cycle of the operation has been performed at experienced workers' standard, trainees attempt 2-, 4- or 8-hr. runs, passing to a longer period only when targets have been achieved on the preceding shorter period.

By the use of these techniques in a wide variety of industries, such as mechanical engineering, electrical engineering, screw making, pottery, hosiery, garment and footwear manufacture, knitting, spinning and weaving, and other less common industries, it has been found possible to reduce the time required for new entrants to attain the level of performance of experiencod workers to between a half and a third of that previously required. Such a reduction in training time, and the higher productivity achieved, lead to economies which usually far exceed the cost of introducing the training scheme. These techniques are also used for the re-training of existing workers whose productivity is below average. The higher output achieved benefits the operators in higher earnings, and the company in lower overhead oosts per unit produced.

In the remainder of the broadsheet Seymour describes the methods he has adopted to analyse the nature of skill and some of the findings. Wider use of these findings could do much to inorease the quality of akill among British operatives.

This most useful broadshect may be obtained from the Institute of Personnel Management, 80 Fetter Lane, London, E.C.4, price $7 s .6 d$.
T. H. HawkINS

\title{
OBSERVED CHARACTERISTICS OF AN ULTRA-HIGH-FREQUENCY SIGNAL TRAVERSING AN AURORAL DISTURBANCE
}

\author{
By J. C. JAMES, L. E. BIRD, R. P. INGALLS and M. L. STONE \\ Lincoln Laboratory, Massachusetts Institute of Technology \\ J. W. B. DAY and G. E. K. LOCKWOOD \\ Defence Research Telecommunications Establishment, Canada \\ AND \\ R. I. PRESNELL \\ Stanford Research Institute, Menlo Park, California
}

\begin{abstract}
$\mathrm{A}^{\mathrm{N}}$ $\mathrm{N}$ experimental study was made to determine the characteristics of ultra-high-frequency signals propagated through auroral-type disturbances. The experiment was performed by illuminating the Moon from a site in the auroral zone and receiving the reflected signals from the Moon at two receiving sites at mid-latitudes.

The transmitter was located at tho Geophysical Institute at College, Alaska. The output power was $10 \mathrm{~kW}$. continuous wave at a frequency of $440 \mathrm{Mc} / \mathrm{s}$. The two receiving sites were located at Shirley Bay, Ontario, near Ottawa, and at the Millstone Hill Ficld Station at Westford, Massachusetts. Each site used an antenna having two orthogonal polarizations.
\end{abstract}

The signals received were studied carefully to determine whether or not there were any differences when the ionosphere was quiet and when the ionosphere was disturbed by auroral activity.

On at least two occasions a strong auroral disturbance was found in the path to the Moon from the transmitting site at College. On these occasions there were two obvious changes in the characteristics of the received signals: (1) there were rapid fluctuations in the polarization angle; and (2) there was an incroase in the rate of fading. However, there was no detectable decrease in average power receivod during the times of these disturbances. 